\title{
Study on Sponge Cake Qualities Made from Hen, Duck and Ostrich Eggs
}

\author{
Jean-Yu Hwang', Yung Shin Shyu², Lieh-Te Yeh², Wen-Chieh Sung,"* \\ ${ }^{1}$ Department of Food Nutrition, Chung Hwa University of Medical Technology, Tainan, Taiwan, R.O.C. \\ ${ }^{2}$ Department of Baking Technology and Management, National Kaohsiung University of Hospitality and Tourism, \\ Kaohsiung, Taiwan, R.O.C. \\ ${ }^{3}$ Department of Food Science, National Taiwan Ocean University, 2 Pei-Ning Road, Keelung, Taiwan, R.O.C. \\ *Corresponding author: sungwill@mail.ntou.edu.tw
}

\begin{abstract}
This study compared hen, duck and ostrich eggs on the physicochemical characteristics of sponge cakes. Hen egg white exhibited a higher overrun and foam stability. The sponge cakes elaborated with hen eggs provided softer texture, higher volume and higher overall acceptability, despite duck egg white had higher foam stability than that of ostrich egg white, whereas duck egg gave harder cake texture than that of ostrich. Sponge cakes made from hen and ostrich eggs had higher $\mathrm{L}$ value, while cakes made from duck egg had significantly higher $\mathrm{b}$ value indicating a more yellow color tome. Sensory evaluation showed that the cakes made from hen egg possessed best quality and acceptability.
\end{abstract}

Keywords: duck egg, ostrich egg, foaming, sponge cake, Texture profile analysis (TPA)

Cite This Article: Jean-Yu Hwang, Yung Shin Shyu, Lieh-Te Yeh, and Wen-Chieh Sung, "Study on Sponge Cake Qualities Made from Hen, Duck and Ostrich Eggs." Journal of Food and Nutrition Research, vol. 6, no. 2 (2018): 110-115. doi: 10.12691/jfnr-6-2-7.

\section{Introduction}

As a tourism industry, leisure farms are far more expanded in Taiwan over the past 10 years. Presently ostrich farming is being established as an alternative form of agriculture and a local tourism spot. The number of ostriches has increased dramatically. Although the market for ostrich products is small by low production rates with demand for eggs, leather and meat much greater than the level of supply [1]. One of the reasons is likely that the lack of information available on the baking characteristics of ostrich eggs.

The foamability and foam stability of hen egg white have been widely studied in the literatures. Hen egg white has the ability to incorporate air by itself or in a mixture with egg yolk and it could hold the aerated structure long enough so that it can be set by heat. Ovalbumin and ovomucoid of egg coagulate during heating and thus give to hen eggs the ability to bind pieces of starch and oil $[2,3,4]$. Eggs go through the following stages during heat coagulation; denaturation flocculation, and insolubility. When the cake batter is heated, some of the egg proteins start to coagulate at a relatively low temperature around $57^{\circ} \mathrm{C}$, to set the foam batter structure; but the batter keep its elasticity and all of the proteins will not throughout coagulate until the cake structure has expanded and developed into its final form at about $82^{\circ} \mathrm{C}$ [5]. It is generally admitted that hen egg white present an excellent formability, but the studies related to the foamability and the foam stability of the other domestic bird, duck and ostrich egg white and their cake texture are relatively scare. Hen egg is widely used in the baking industry, because its suitable functions and properties in many different ways for baking products, in which it has certain desirable characteristics. Hen egg not only adds color and flavor, binds emulsifies, improves nutrition, retains moisture, tenderizes, and it leavens the baking products. However, duck and ostrich eggs remain far less studied in the baking industry than hen eggs. A comparison of the physicochemical properties of hen, duck and ostrich egg and the qualities of their baking product still lacks in the literature. The purpose of this work is therefore to gain a briefly understanding of the role of different kind of eggs on the physicochemical characteristics of sponge cakes and to highlight similarities and differences among hen, duct and ostrich egg resulting from whipping and baking process.

\section{Materials and Methods}

\subsection{Raw Materials and Chemicals}

Cake flour, milk, soybean oil were obtained from Uni-Present Enterprises Corporation (Tainan, Taiwan). Ostrich eggs were supplied by Jiaxing Leisure Farms (Ping Tung, Taiwan). Hen and duck eggs were purchased from local market. All chemicals used in this work were of analytical grade. 


\subsection{Sponge Cake Preparation}

Formulations used for the sponge cakes are eggs (525 $\mathrm{g})$, cake flour (300 g), sugar (450 g), milk (60 g), soybean oil (60 g), and salt (9 g). Whole eggs and salt were poured into a bowl and mixed in a vertical mixer (Jen Dah Food Machinery, Chiayi, Taiwan) with a whisk attachment to whip eggs at a high speed for 3 minutes. Sucrose was added during whipping. The sifted cake flour, milk, and soybean oil were gradually blended into the batter. The cake batter $(350 \mathrm{~g})$ was transferred into an 8 -inch cake tin coated with baking paper at the bottom and bake at $180^{\circ} \mathrm{C} / 180^{\circ} \mathrm{C}$ in a preheated electric oven for 30 minutes.

\subsection{Method for Foam Characterization}

Overrun: The foaming ability of different egg whites was deduced from overrun measurements. Overrun values were derived from density measurements [6]. These were carried out during the foaming process. A Kitchen Aid Ultra Power Mixer (Kitchen Aid, USA) with a $4.3 \mathrm{~L}$ stationary bowl and rotating beater was used for foam formation. The egg white $(200 \mathrm{~mL})$ was whipped at speed setting 10 (Planetary speed at $265 \mathrm{rpm}$ ) for a period of time $(0,60 \mathrm{sec}, 120 \mathrm{sec}, 180 \mathrm{sec}, 240 \mathrm{sec})$. The density of the foam was measured as the mass-to-volume ratio of a foam egg white using a glass cup of known volume. Overrun can be expressed as $\Phi=100 \times(\rho L-\rho F) / \rho F$.

Foam stability: Drainage rate was determined by the weight of the drained liquid filled in a 20 mesh sieve during 6 hours. For the determination of the foam stability, $200 \mathrm{~mL}$ of egg white was beaten in a kitchen aid ultra mixer at speed setting 10 for 3 minutes. The foams were leaved on a 20 mesh sieve, transferred into a glass funnel, fitted with a 20 mesh sieve. The liquid draining from the foam was collected in a glass beaker, on top of an electronic balance. The foam stability was defined as the percentage of egg white still present in the foam after 6 hours compared to the situation after whipping [7]. Drainage was determined by recording all the 60 minutes for a 6 hours cycle.

\subsection{Physical Characteristics of Sponge Cake}

Chromaticity testing: The colour determinations of different egg yolks, cake crumb and top crust were measured using a colour measurement spectrophotometer (Model TC-1, Tokyo Den shoku Co., Japan) to determine lightness (L), red content (a) and yellow content (b). A white reference plate $(Y=95.43, X=93.49, Z=113.21)$ was used as a standard. White index (WI) was calculated as following formula: $\mathrm{WI}=100-\left((100-\mathrm{L})^{2}+\mathrm{a}^{2}+\mathrm{b}^{2}\right)^{1 / 2}$.

Texture Profile Analysis (TPA): Hardness of cakes were tested with the TA.XT2 Texture Analyzer (Stable Micro Systems Co., Ltd., Haslemere, England) and a No $\mathrm{P} / 0.5 \mathrm{~S} / 0.5$ " Diameter cylinder probe according the methods of Shyu et al. [8]. Test speed was $10 \mathrm{~mm} / \mathrm{min}$, and distance was $15 \mathrm{~mm}$ (50\% compression). Internal cake crumb was sliced into $30 \times 30 \times 30 \mathrm{~mm}$ samples to be measured. Cake samples were sealed in $1 \mathrm{Kg}$ polyethylene (PE) bags after cooling and held at room temperature $\left(25^{\circ} \mathrm{C}\right)$ for further testing. Hardness was recorded for 3 days storage duration.
Water activity: Five grams of sample were put in a Pawkit water activity meter (Pullman, WA) to equilibrate for 3 minutes before measurement. For cake crust and crumb attribute determinations, whole cake was halved along the height. The upper half cake was used for crust evaluation and the low half for crumb evaluation.

\subsection{Sensory Evaluation}

Sponge cakes were served to 20 panelists to evaluate overall acceptability. Twenty male and female students of the Department of Baking Technology and Management between the ages of 20 and 24 were participants on the panel. Panelists were instructed to evaluate overall acceptability using a nine-point hedonic scale ranging from "extreme satisfaction=9" to "extreme dissatisfaction=1". A one-to-nine hedonic scale was used for evaluating the intensity of flavor, manual and mouth hardness, and crust and crumb uniformity together with an overall acceptability test. Sponge cakes coded with three digits were supplied to them. The sensory data present was means for 20 panelists.

\subsection{Statistical Analysis}

A completely randomized block design was used with three replications per treatment with three subsamples per replication. Data were analyzed by analysis of variance program using the Statistical Analysis System (SAS Institute Inc., 2000). Duncan's test was used to identify differences between treatments a significance level of $5 \%$ $(\mathrm{p}<0.05)$.

\section{Results and Discussion}

Table 1 gives the mean percentage differences of the basic egg parts between species and component fraction. Percentage of egg shells from ostrich was significantly 2.0 times higher than that of hen and duck (Table 1). Ostriches (Struthio camelus) are the largest living flightless birds in the world. Average egg weight is about 1461g (usual range 1298-1607g) [9]. It should be noted that much higher percentage of egg white were demonstrated for hen eggs compared to the other species. The present results indicated that much higher percentage of egg yolk was measured for duck egg. As can be seen in Table 2 egg yolk lightness (L) values of hen was notably higher than those of duck and Ostrich egg yolk. In Table 2 duck egg yolk had the highest a value and Ostrich egg yolk had the lowest $b$ value. The greatest differences in colour were observed in duck egg yolks, mainly due to the highest a value. The appearance of various eggs was showed at Figure 1.

The foaming properties of proteins are usually characterized by two main parameters; namely, foamability and foam stability [10]. Foam stability is determined by measuring over time either the rate of liquid drainage or the rate of decrease in foam volume due to bubble coalescence. Foam stability is a key parameter for the shelf life of food foams, and must be maintained when subjected to a variety of process, such heating, mixing and cutting [11]. Egg white has the ability to form very stable foams, when egg white is beaten by mixer and air is incorporated large area of 
new surfaces are formed and a small percent of proteins will denature and spread as a monomolecular layer over the surfaces to produce a stable foam. Figure 2 shows that the maximum overrun achieved by hen egg white. Foam overrun of egg white decreased in the order: hen $>$ ostrich $>$ duck. The foam ability of egg white was deduced from overrun measurements. Hen egg white protein has the ability to incorporate air by itself to hold the aerated structure long enough. Campbell and Mougeot [12] reported hen egg white developed high foam volumes with overrun values of around 500-800\%. Foam made from hen, ostrich and duck egg white overruns was $812 \%$, $688 \%$ and $408 \%$, respectively. The foaming of whole egg and yolk is similar to but more complex than the foaming of egg white. There is a large amount of lipids present and these lipids must be in a highly emulsified state in order for the batter to develop stable foam. The foam overrun and stability were much evident in hen egg white. The foam stability of ostrich egg white drops more quickly during the first three hours (Figure 3 ). The foam stabilities of different egg whites after 180 minutes drainage were $60.2 \%$ for hen, $55.8 \%$ for duck, and $47.4 \%$ for ostrich. Protein aggregates adsorb at the interface and increase the interfacial viscoelasticity, thus enhancing foam stabilization $[13,14]$. The aggregates which do not absorb to the inter face can become confined into foam films and a percolation process, leading to the formation of a gel-like network which might slow down liquid drainage [15]. The foams whipped from duck egg white took more time to foam, but they were more stable than the foams prepared from ostrich. Foam stability can be enhanced in several ways. There are three important processes that determine the stability of foam; film drainage, bubble coalescence, and bubble disproportion. Film drainage refers to liquid flowing from the foam, driven by the gravitational force. The rate of drainage is function of rheological properties of the bulk phase. For this process the most important surface rheological parameters appear to be the surface dilational viscosity and the surface dilational elasticity. In bubble coalescence the thin films between two bubbles collapse, and the two bubbles merge to form one larger bubble. The stability against film rupture will increase for increasing surface tension and decreasing bubble size. Bubble disproportion also referred to as Oswald ripening is the process where gas from the smaller bubbles diffuses through the liquid phase to the larger bubbles through the liquid phase to the larger bubbles. This process is driven by the difference in Laplace pressure between the smaller and larger bubbles, and results in a shrinking of the small bubbles, and growth of the larger bubbles, and hence in a broadening of the bubble size distribution of the foam. Eventually, when the smaller bubbles completely disappear, this results in coarsening of the foam.

Table 1. Weight and component fractions of hen, duck and ostrich egg

\begin{tabular}{|c|c|c|c|c|c|}
\hline & Whole egg $(\mathrm{g})$ & Shell (\%) & Egg white (\%) & Egg yolk (\%) & Egg white/Egg yolk \\
\hline Hen egg & $60.66 \pm 3.96$ & $10.65 \pm 0.71^{b}$ & $62.70 \pm 3.20^{\mathrm{a}}$ & $26.65 \pm 3.90^{b}$ & $2.39 \pm 0.25^{\mathrm{a}}$ \\
\hline Duck egg & $73.18 \pm 4.50$ & $10.40 \pm 1.26^{\mathrm{b}}$ & $56.79 \pm 1.67^{b}$ & $32.81 \pm 1.09^{\mathrm{a}}$ & $1.73 \pm 0.08^{b}$ \\
\hline Ostrich egg & $1358.5 \pm 106.8$ & $20.75 \pm 0.30^{\mathrm{a}}$ & $53.10 \pm 2.02^{b}$ & $26.15 \pm 1.25^{b}$ & $2.03 \pm 0.09^{\mathrm{ab}}$ \\
\hline
\end{tabular}

1.The values are mean \pm standard deviation

2. ${ }^{\mathrm{a}-\mathrm{c}}$ The values in the same column followed by different superscripts were

significantly different. $(p<0.05)$

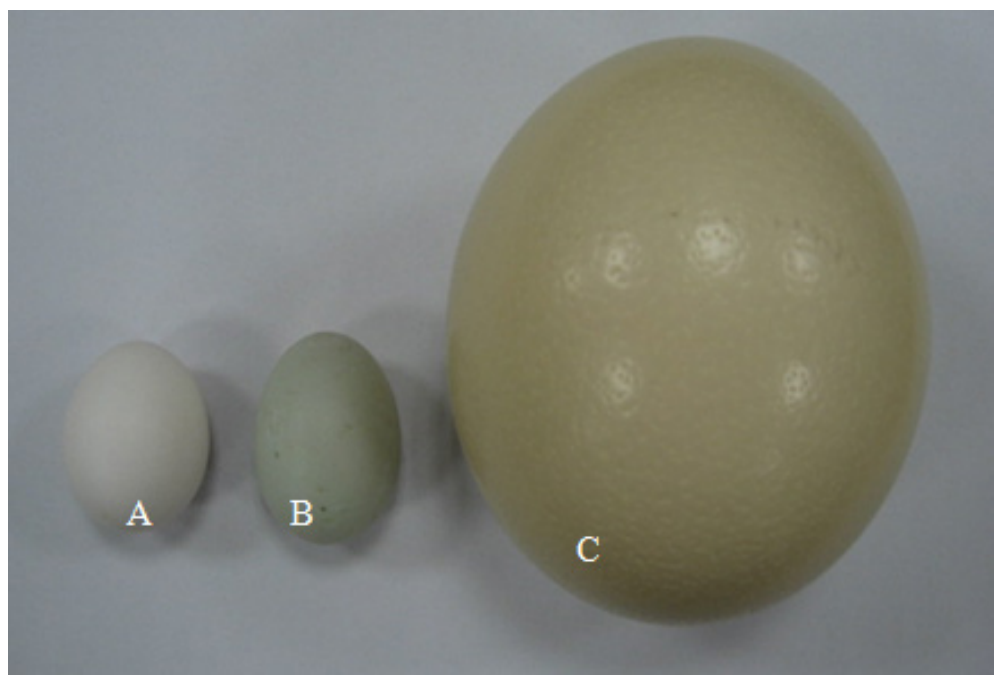

Figure 1. Appearance of (A) hen egg; (B) duck egg; (C) ostrich egg

Table 2. Yolk color of hen, duck and ostrich egg

\begin{tabular}{cccc}
\hline & $\mathrm{L}$ & $\mathrm{a}$ & $\mathrm{b}$ \\
\hline Hen egg yolk & $57.47 \pm 0.17^{\mathrm{a}}$ & $9.80 \pm 0.05^{\mathrm{b}}$ & $72.07 \pm 0.22^{\mathrm{a}}$ \\
Duck egg yolk & $48.91 \pm 1.15^{\mathrm{b}}$ & $23.76 \pm 3.72^{\mathrm{a}}$ & $72.16 \pm 1.79^{\mathrm{a}}$ \\
Ostrich egg yolk & $47.72 \pm 0.04^{\mathrm{b}}$ & $5.08 \pm 0.03^{\mathrm{c}}$ & $40.07 \pm 0.03^{\mathrm{b}}$ \\
\hline
\end{tabular}

1. The values are mean \pm standard deviation

$2{ }^{a-c}$ The values in the same column followed by different superscripts were significantly different. $(p<0.05)$ 


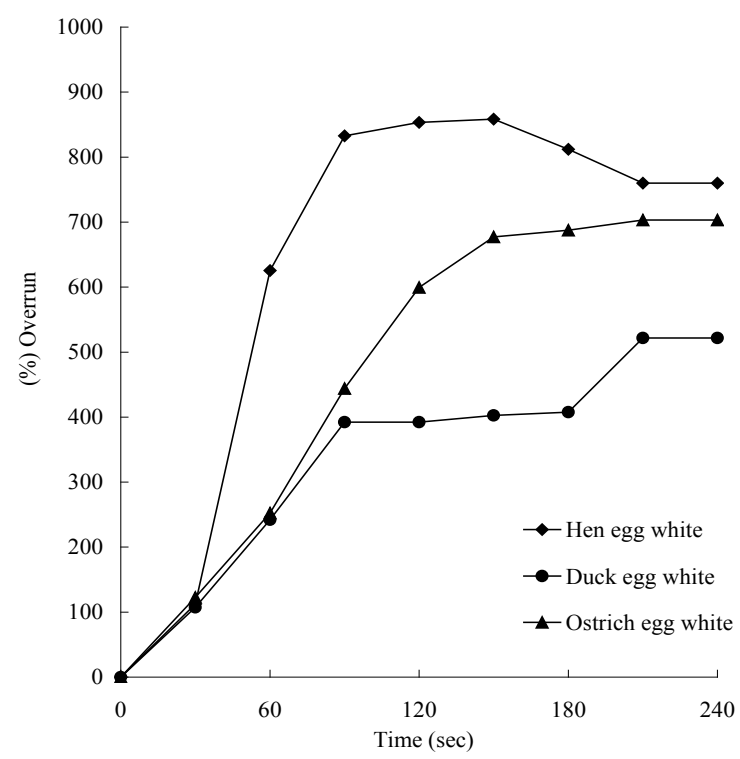

Figure 2. Comparison of foam overrun of hen, duck and ostrich egg white

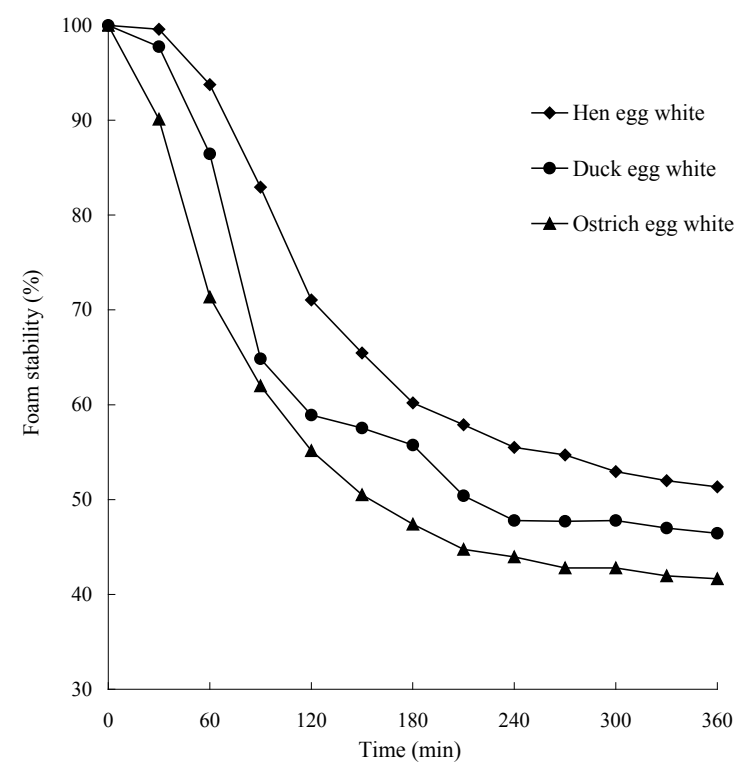

Figure 3. Comparison of foam stability of hen, duck and ostrich egg white

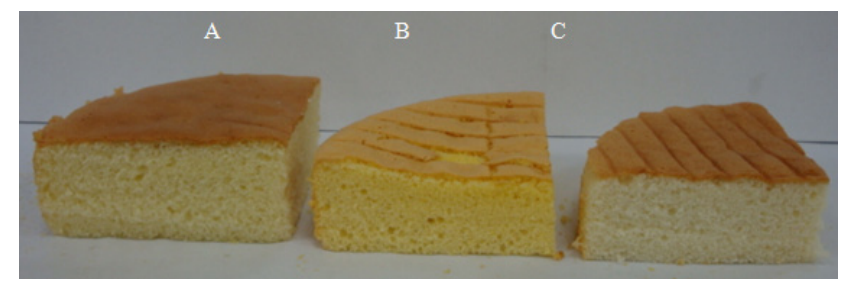

Figure 4. Photographs of sponge cakes (A. hen egg; B. duck egg; C. Ostrich egg)

Table 3. Crumb color of sponge cakes of hen, duck and ostrich egg

\begin{tabular}{ccccc}
\hline & $\mathrm{L}$ & $\mathrm{a}$ & $\mathrm{b}$ & W.I. \\
\hline Hen egg & $83.66 \pm 1.06^{\mathrm{a}}$ & $0.017 \pm 0.008^{\mathrm{b}}$ & $29.18 \pm 0.24^{\mathrm{b}}$ & $66.55 \pm 0.55^{\mathrm{b}}$ \\
Duck egg & $81.30 \pm 0.60^{\mathrm{b}}$ & $5.067 \pm 0.502^{\mathrm{a}}$ & $40.88 \pm 0.59^{\mathrm{a}}$ & $54.62 \pm 0.80^{\mathrm{c}}$ \\
Ostrich egg & $84.12 \pm 0.15^{\mathrm{a}}$ & $0.023 \pm 0.010^{\mathrm{b}}$ & $22.85 \pm 0.25^{\mathrm{c}}$ & $72.17 \pm 0.22^{\mathrm{a}}$ \\
\hline
\end{tabular}

1. The values are mean \pm standard deviation

2. ${ }^{\mathrm{a}-\mathrm{c}}$ The values in the same column followed by different superscripts were significantly different. $(p<0.05)$.
Sponge cakes manufactured with duck eggs were in general lighter, redder and more yellow than sponge cakes made from hen and ostrich eggs (Figure 4). As can be seen in Table 3, crumb lightness $\mathrm{L}$ value of duck egg sponge cakes was lower than those of hen and ostrich egg sponge cake. The highest difference in crumb chromatic parameter $a$ and $b$ values were obtained with duck egg (Table 3). This fact was associated with the high a value in duck egg yolk and high yolk percentage in duck egg (Table 2). Sponge cakes became darker (lower L value) as the duck egg used. The effect of the egg yolks on the crumb colour was more evident in $\mathrm{a}$ and $\mathrm{b}$ values. Cake crumb does not reach temperatures above $100^{\circ} \mathrm{C}$, so the Maillard reaction or caramelization by sugars fail to take place. Therefore, crumb colour must be the result of the egg yolk colour and their interaction [16].

Cakes elaborated with ostrich egg presented the highest white index, mainly due the lowest $\mathrm{L}$, $\mathrm{a}$ and $\mathrm{b}$ value in egg yolk. In Table 4 the height and sensory acceptability of sponge cakes can be observed. The cakes elaborated with hen were higher in volume and more acceptable than those caked made from duck and ostrich eggs. Cake volumes were most influenced by the overrun and foam stability of egg white. In general, the cake volume was lower in sponge cake made from duck egg, although it had higher foam stability than that of ostrich egg white. In sponge cakes, as egg white/egg yolk ratio increased, cake volume increased. Acceptability decreased when the cake volume decreased. Sponge cakes made from hen eggs have a distinct cake flavor, but off flavor in duck and ostrich sponge cakes was mentioned by panelists. The change of water activity over the storage time can be seen in Figure 5, A(crumb) and B(curst). The influence of storage time on the water activity of cake crumb was not significant different in any species, although a gradual decrease in water activity was observed. After 3 days of storage, the water activities of the crust increase. In general, water activity increases in crust is mainly attributed to crumb dehydration, which phenomena had reported by Czuchajowska and Pomeranz [17]. Unlike bread staling, hardening phenomena in cakes were not obvious. In sponge cake, eggs help to retain moisture during baking and also during storage. Eggs, sugar, and oils bind the ingredients together and offer a barrier through which it is difficult for moisture to escape. After 3 days of storage, the sponge cakes elaborated with different eggs presented similar firmness increasing trend, however, the initial firmness of sponge cake made from duck egg was high due to the low overrun and foam stability in egg white, which also had a significant effect on the overall acceptability of sponge cake (Figure 6).

Table 4. Height and sensory acceptability of sponge cakes of hen, duck and ostrich egg

\begin{tabular}{ccc}
\hline & Height $(\mathrm{cm})$ & Acceptability \\
\hline Hen egg & $4.7 \pm 0.2^{\mathrm{a}}$ & $6.9 \pm 1.1^{\mathrm{a}}$ \\
Duck egg & $3.3 \pm 0.1^{\mathrm{c}}$ & $3.4 \pm 1.2^{\mathrm{c}}$ \\
Ostrich egg & $3.7 \pm 0.1^{\mathrm{b}}$ & $4.6 \pm 1.0^{\mathrm{b}}$ \\
\hline
\end{tabular}

1. The values are mean \pm standard deviation

$2 .^{a-c}$ The values in the same column followed by different superscripts were significantly different. $(p<0.05)$

3 . Nine point hedonic scale ' $1=$ extreme dissatisfaction', ' $5=$ moderate', ' $9=$ extreme satisfaction' 

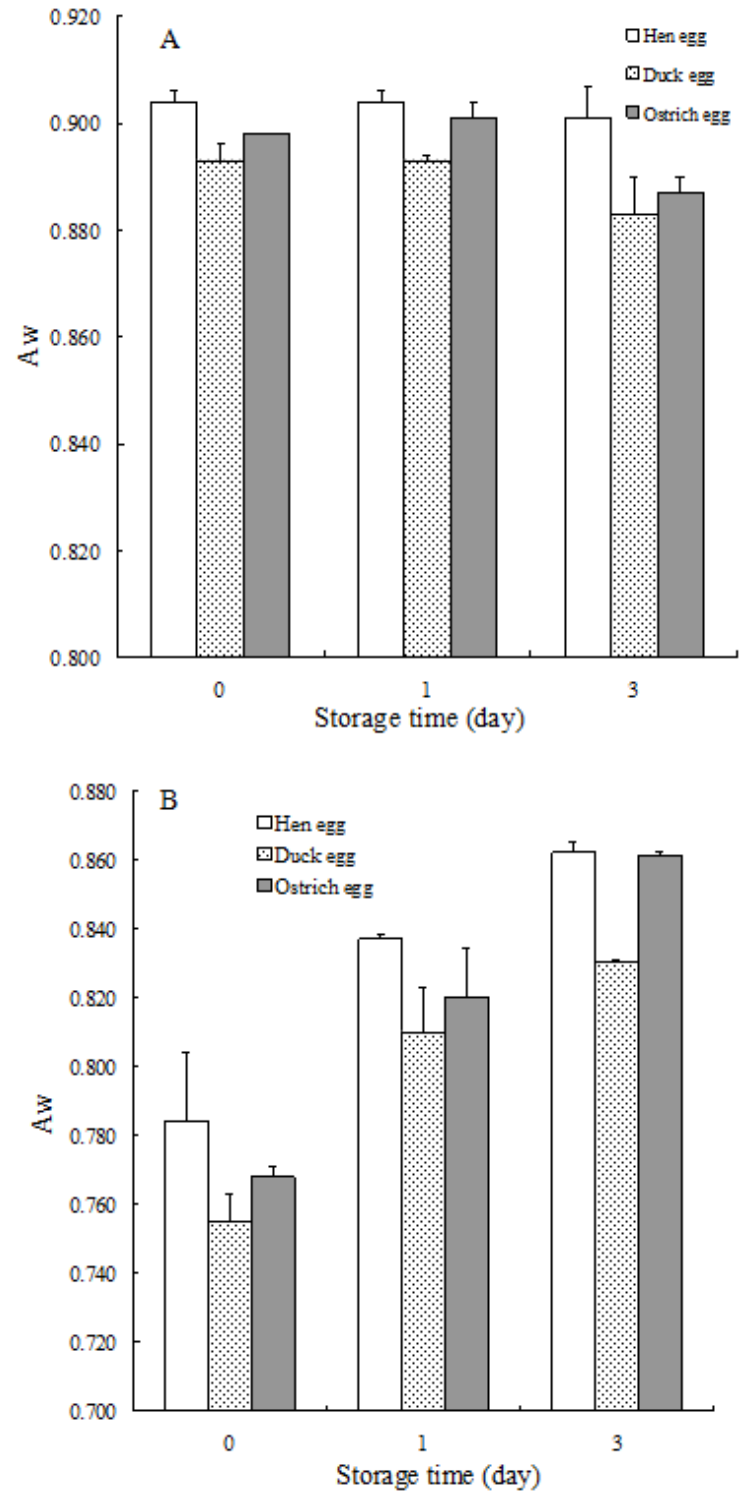

Figure 5. Effect of hen, duck and ostrich egg on the changes of the water activities (Aw) of sponge cake during storage(A. Crumb, B.Crust)

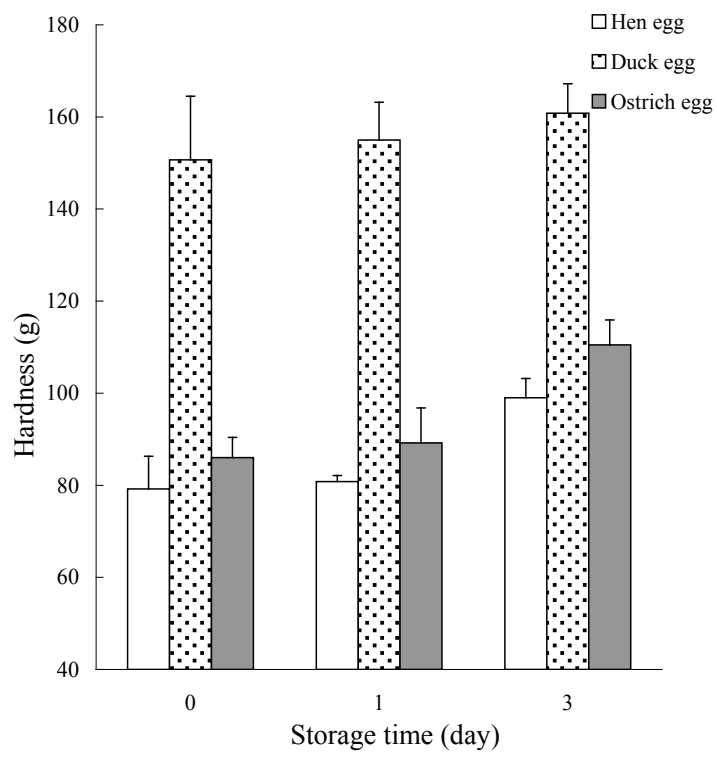

Figure 6. Effect of hen, duck and ostrich egg on the changes of the hardness of sponge cakes during storage

\section{Conclusion}

The results of the present study show duck egg and ostrich egg could be used as ingredient in the elaboration of sponge cakes. Hen egg white has better overrun and foam stability to hold aerated structure. In general, low the egg white/egg yolk ratio, overrun, and foam stability leads to low cake volume and less acceptable on the texture of sponge cake. The sponge cakes made from hen eggs were higher in volume and more acceptable than cakes made from duck and ostrich eggs in the study. The egg yolk colour and its percentage in egg will influence the appearance of its baking products.

\section{References}

[1] Deeming, D.C. and Angel, C.R, "Introduction to the ratites and farming operations around the world. Improving our understanding of ratites in a farming environment," in Ratite Conference, Oxfordshire, UK, 1996, 1-4.

[2] Ngo, W.H. and Taranto, M.V, "Effect of sucrose level on the rhelogical properties of cake batters," Cereal Foods World, 31(1). 317-322. 1986.

[3] Shelke, K., Faubion, J.M. and Hoseney, R.C, "The dynamics of cake baking as studied by a combination of viscometry and electrical resistance oven heating," Cereal Chemistry, 67(6). 575580. 1990.

[4] Taranto, M.V, Structural and textural characteristics of baked goods. In: M. Peleg, \& E. B. Bagley (Eds.), Physical properties of foods, AVI Publishing, Westport, CT, 1983, 229-265.

[5] Dickinson, E. and Stainsby, G, Colloids in food, Applied Science Publishers, London and New York, 1982.

[6] Davis, J.P. and Foegeding, E.A, "Comparisons of the foaming and interfacial properties of whey isolate and egg white proteins," Colloids and Surfaces, 54(2). 200-210. 2007.

[7] Kitabatake N., Tani Y. and Doi, E, "Rheological properties of heat-induced ovalbumin gels prepared by two-step one-step heating methods," Journal of Food Science, 54(6). 1632-1638. 1989.

[8] Shyu, Y.S., Hwang, J.Y. and Hsu, C.K, "Improving the rheological and thermal properties of wheat dough by the addition of $\gamma$-polyglutamic acid," LWT - Food Science and Technology, 41(6). 982-987. 2008.

[9] Ar, A., Meir, M., Aizik, N. and Campi, D, "Standard values and ranges of ostrich egg parameters as a basis for proper artificial incubation," in D. C. Deeming (Ed.), Improving our Understanding of Ratites in a Farming Environment: Proceedings of the 1st International Ratite Congress. Ratite Conference, Oxfordshire, UK, 1996, 144-145.

[10] Raikos, V., Campbell, L. and Euston, S.R, "Effects of sucrose and sodium chloride on foaming properties of egg white proteins," Food Research International, 40(3). 347-355. 2007.

[11] Ercelebi, E.A. and Ibanoglu, E, "Effects of ionic strength on the foaming properties of whey protein isolate and egg white in the presence of polysaccharides," Journal of Food Processing and Preservation, 33(4). 513-526. 2009.

[12] Campbell, G.M. and Mougeot, E, "Creation and characterization of aerated food products," Trends in Food Science and Technology, 10(9). 283-296. 1999.

[13] Davis, J.P. and Foegeding, E.A, "Foaming and interfacial properties of polymerized whey protein isolate," Food Chemistry and Toxicology, 69(5). 404-410. 2004.

[14] Rullier, B., Novales, B. and Axelos, M. "Effect of protein aggregates on foaming properties of $\beta$-Lactoglobulin," Colloids and surfaces A: Physicochemical and Engineering Aspects, 330(23). $96-102.2008$

[15] Schmitt, C. Bovay, C., Rouvet, M., Shojaei-Rami, S. and Kolodziejczyk, E, "Whey protein soluble aggregates from heating with $\mathrm{NaCl}$ : Physicochemical interfacial, and foaming properties," Languir, 23(8). 4155-4166. 2007. 
[16] Gomez, M., Oliete, B., Rosell, C. M., Pando, V. and Fernandez, E, "Studies on cake quality made of wheat-chickpea flour blends," LWT-Food Science and Technology, 41(9). 1701-1709. 2008.
[17] Czuchajowska, Z. and Pomeranz, Y, "Differential scanning calorimetry, water activity, and moisture contents in crumb center and near-crust zones of bread during storage," Cereal Chemistry, 66(4). 305-309. 1989. 